\title{
Relación entre origen social e inserción laboral de los graduados universitarios
}

\author{
Relationship between social origin and labor insertion of university graduates
}

Fachelli, Sandra ${ }^{(1)}$; Navarro-Cendejas, José ${ }^{(2)}$;

(1) Universidad de Barcelona. (2) Centro de Investigación y Docencia Económicas (México)

\begin{abstract}
Resumen
Este artículo tiene dos objetivos. En primer lugar, queremos analizar si el peso del origen social de los graduados universitarios influye en la inserción laboral, tomando como indicador los ingresos que obtienen los titulados que trabajan, cuando controlamos la titulación obtenida. En segundo lugar, intentamos observar si los graduados universitarios provenientes de orígenes sociales más desfavorecidos se encuentran más desocupados y más inactivos que los provenientes de hogares con más recursos. Para tal fin analizamos a los titulados que egresaron de universidades públicas catalanas en el curso 2006-2007, entrevistados por la “Agencia Catalana per a la Qualitat del Sistema Universitari de Catalunya” (AQU Catalunya) en el primer trimestre de 2011. La metodología utilizada se basa en técnicas estadísticas bivariadas (tablas de contingencia) y análisis multivariado (regresión logística binomial). Los resultados obtenidos en la presente contribución nos obligan a reformular las hipótesis de partida, pues los hallazgos muestran que, aun tomando en cuenta la titulación, no se observa una influencia significativa del origen social en la inserción laboral de esta cohorte concreta de graduados universitarios
\end{abstract}

Fecha de recepción 20 de febrero de 2015

Fecha de aprobación 16 de Noviembre 2015

Fecha de publicación 15 de Diciembre 2015

\section{Palabras clave:}

Graduados universitarios, origen social, inserción laboral, especialidad de estudios, relación empleo-formación

\begin{abstract}
This article has two primary objectives. Firstly, we aim to examine whether the weight of social origin of university graduates influences the labour market entry, using the wages as an indicator of graduates' job quality, once controlled the degree obtained. Secondly, we want to observe whether graduates from disadvantaged social backgrounds are more unemployed and inactive than those from households with more resources. In order to achieve these purposes, we analyzed a sample of graduates from Catalan public universities in 2006-2007 interviewed by the Catalan Agency for the Quality of University System (AQU) in the first trimester of 2011. The methodology is based on bivariate statistical techniques (contingency tables) and multivariate analysis (binomial logistic regression). The results obtained in the present article leads us to reformulate our original hypothesis, as the findings show that even taking into account the specific degree obtained by graduates, we do not observed a significant influence of social background on the employment of university graduates in this cohort.
\end{abstract}

Reception Date 2015 February 20

Approval Date 2015 November 16

Publication Date: 2015 December 15

\section{Keywords:}

University graduates, social origin, labour insertion, field of study, training-employment relationship

El debate sobre la expansión universitaria ha estado desde hace varios años cruzado por el interés de desvelar de qué manera la estructura social sigue pesando en los niveles educativos más altos de la sociedad, y a su vez

cómo la estructura educativa tiene
consecuencias en otros ámbitos como la estructura ocupacional. En el caso de Francia, por ejemplo, Baudelot et al. (1981) han observado cómo el crecimiento cuantitativo de

\section{Autor de contacto / Corresponding author}

Fachelli, Sandra. Universitat Autònoma de Barcelona. Facultat de Ciències Polítiques i Sociología.

Despatx B3/ - 107. 08193 Bellaterra, Barcelona. sandra.fachelli@ub.edu 
la universidad en los años sesenta tuvo un marcado acento clasista por ramas educativas o por carreras específicas: medicina podía considerarse como la carrera de los "varones burgueses", letras para las mujeres de todas las clases sociales, farmacia para hijas de directivos, y estudios científicos para varones de cualquier clase social.

En el mismo sentido se ha enfatizado que las ventajas sociales, que se reproducen de padres a hijos, también pueden observarse en las diferentes vías del sistema educativo (Calmand \& Epiphane, 2012; Lucas, 2001; Triventi, 2011a) constatándose la tendencia de los hijos de clases más aventajadas hacia vías más académicas mientras que los hijos de clases más bajas tienden a inscribirse más en programas de tipo vocacional, por ejemplo, relacionados con áreas técnicas (Van de Werfhorst \& Luijkx, 2010).

También se sabe que la decisión de qué carrera estudiar está correlacionada con la anticipación que hacen los estudiantes y sus familias sobre sus oportunidades de éxito académico. Una carrera de ciclo largo implica una inversión prolongada en años, lo cual puede representar un riesgo de fracaso para aquellos que no han tenido una buena trayectoria académica preuniversitaria (Salas, 2005; Troiano \& Elias, 2013).

Existe una amplia literatura que estudia el impacto de la titulación en la composición social de la universidad (Gerber \& Cheung, 2008). Por ejemplo, Van de Werfhorst y Luijkx (2010) estudiaron la influencia de la ocupación de los padres en el campo de estudios elegidos por los hijos en el caso de los Países Bajos, a partir de la hipótesis de que los hijos estarían sobrerrepresentados en campos similares al de la ocupación del padre. Estos investigadores efectivamente encontraron que, controlando la relación entre la clase social y el nivel educativo, los hijos eligen con frecuencia especialidades de estudio con afinidad al dominio ocupacional de los padres.

En definitiva, parece estar comprobado que al interior de la universidad siguen operando mecanismos de estratificación en la composición social de las titulaciones (Gerber \& Cheung, 2008; Triventi, 2011) pero también intervienen factores individuales. Troiano $\mathrm{y}$ Elias (Troiano \& Elias, 2013) presentan un modelo que permite comprender los factores que intervienen en la elección de una carrera, integrando tanto aspectos individuales como colectivos. Así, la elección de la carrera sería resultado de un balance entre preferencias (aspiraciones personales, sociales y de la disposición al estudio) y riesgos que surgen de la evaluación del coste relativo (costes directos, indirectos y de oportunidad, así como los ingresos) de dicha elección y de la probabilidad de éxito (opciones posibles, capacidades propias, duración y dificultades previstas).

Lo que sucede dentro de la universidad está fuera del alcance de este artículo, aquí nos centramos en los resultados de inserción laboral, sin embargo hacemos una mirada retrospectiva al preguntarnos ¿Será la titulación un elemento importante de diferenciación para explicar la influencia del origen social en la inserción laboral temprana del graduado de la universidad pública catalana?

Anteriormente, hemos tenido ocasión de ver que los filtros que operan fuertemente para acceder a la universidad, estudiados tradicionalmente en el campo de la sociología de la educación, se ven debilitados en aquellos que logran finalizar la universidad (Planas \& Fachelli, 2010). Este trabajo mostró que el impacto del origen social a nivel agregado tenía una pequeña influencia en algunas categorías concretas pero en cuyo caso la capacidad explicativa del modelo era muy baja cuando se usaban los ingresos laborales de los graduados $(8,7 \%)$ y aún menor cuando se observaba la calidad de la ocupación (2\%) y en ambos casos, el nivel educativo de los padres no tenía ningún impacto (Planas \& Fachelli, 2010: 104-105).

Una razón que podría atribuirse a ese comportamiento es que tal vez formaba parte de una particularidad del caso catalán o de la cohorte analizada y que en realidad había que 
analizar una población más amplia. Esas razones fueron atendidas y nos llevaron a analizar una cohorte que más o menos tuviera el mismo tiempo de inserción en el mercado de trabajo tomando la Encuesta de Condiciones de Vida de 2005, es decir, graduados en España entre 1999 y 2002. Los resultados obtenidos nos sorprendieron mostrando que solo el sexo y la propia ocupación influían en el salario obtenido pero no así la ocupación y el nivel educativo de los padres de los graduados (Fachelli, Torrents \& NavarroCendejas, 2014).

Entonces surgió la crítica y la necesidad de saber si este comportamiento se mantenía en el tiempo. La nueva hipótesis a testar fue si la influencia del origen social desaparecía en la inserción temprana, pero volvía a aparecer con el paso de los años a través de las redes sociales, de modo que el graduado en educación superior gozaba por un tiempo de la liberación de las cadenas de la adscripción pero el hecho de volver a cargarlas era sólo una cuestión de tiempo. Con este interrogante decidimos extender el análisis en cohortes sucesivas considerando gente que se había graduado siete años antes del 2005 hasta treinta años antes. Utilizamos 6 cohortes que cubrieron todo el período democrático. Este análisis muestra que si bien las barreras económicas y culturales pesan en la inserción laboral de la población en general, entre los universitarios se diluyen desde su inserción laboral temprana y esta situación se mantiene en el tiempo (Torrents \& Fachelli, 2015).

Pero los expertos argumentaron que entonces la explicación está en que la agrupación de los datos esconde realidades más complejas y diversas, y que será posible sacar conclusiones generales cuando la mirada se haga con mayor nivel de desagregación, esto es, por áreas de investigación, subáreas o incluso y lo más importante: por titulación.

A las primeras dos cuestiones respondimos que en el trabajo de 2010 para los graduados catalanes se había indagado diferencias por área y subárea. La bondad de ajuste de los modelos que exploraban la influencia del origen social tenían capacidades explicativas muy bajas, entre el 2 y 7\% según el área, siendo responsables de dicho coeficiente muchas veces variables como sexo, nota de acceso o expediente académico, más que el propio origen. El rastreo por subárea fue más fructífero: dos subáreas dentro de Humanidades, tres dentro de Económicas, dos dentro de Ciencias sociales, una en Ciencias experimentales, una en Ciencias de la Salud y tres en Técnicas acusaban que algunas de las características analizadas en el modelo influía en la remuneración obtenida) (Planas \& Fachelli, 2010).

Respaldando aquellos hallazgos Julio Carabaña y Gloria de la Fuente (2015) analizan a los graduados de la Facultad de Ciencias Sociales y Humanidades de Universidad Complutense de Madrid en el año 2003 y preocupados por este mismo tema, encuentran tres titulaciones donde el origen social se hace notar y destacan que el impacto de la familia de origen en el destino profesional y en los ingresos disminuía una vez que se controlaban las titulaciones $y$ además eran pocas las titulaciones en las que se mantenía (Carabaña \& De la Fuente, 2015)

No obstante reflexionando nuevamente sobre aquellos resultados obtenidos en 2010 resolvimos recoger la inquietud de nuestros críticos expertos sobre la importancia del análisis desagregado, y esta vez bajamos al último peldaño de agregación: la titulación.

Por tal motivo, atendiendo la amplia bibliografía internacional y a las sugerencias recibidas sobre la importancia del efecto estratificador que puede tener la titulación en el estudiante universitario, decidimos emprender este estudio que presentamos a continuación. Observamos entonces si la influencia del origen social pesa en la inserción laboral de los graduados universitarios, prestando atención a la titulación obtenida. Con este objetivo abordamos el estudio de graduados catalanes en el curso 2006-2007 que fueron entrevistados en 2011. 


\section{Método}

\section{Población analizada}

Los datos provienen de la cuarta Encuesta de Inserción Laboral a la Población Graduada de las Universidades catalanas (AQU Catalunya, 2011). Se trata de un estudio que realiza la Agencia para la Calidad del Sistema Universitario de Cataluña (AQU Catalunya), desde el año 2001, con una muestra probabilística de titulados universitarios que obtuvieron el grado cuatro años antes de contestar la encuesta [1]. Para esta investigación se tuvo acceso a los microdatos correspondientes a la encuesta 2011, conformada por graduados que terminaron los estudios en 2007. De la muestra total de titulados de esa cohorte se seleccionaron a aquellos que egresaron de las universidades públicas (11.843 encuestados). Este conjunto de titulados se distribuye en un total de 119 titulaciones, las cuales hemos analizados sin aplicar ningún tipo de agrupación entre ellas.

\section{Hipótesis}

Dado que el peso del origen social en múltiples etapas de la vida es un factor determinante para explicar la limitación de ciertas oportunidades y que hemos detectado un comportamiento no esperado en trabajos anteriores para el caso de los graduados universitarios (Planas \& Fachelli, 2010; Fachelli, Torrents \& Navarro-Cendejas, 2014; Torrents \& Fachelli, 2015), dedicamos ahora reunir evidencias acerca de dicho comportamiento. Es por ello que analizamos el peso del origen social en los graduados universitarios que han egresado de la universidad y tienen una inserción laboral temprana (3 o 4 años después de graduarse). Lo analizado hasta el momento nos señala que existe un proceso de desigualdad muy pronunciado para acceder a la universidad (Torrentes, 2012), un proceso dentro de la universidad donde podría decirse que el eje articulador de las diferencias pasa en mayor medida por la titulación elegida (NavarroCendejas, 2013) y ello nos brinda las bases para analizar el siguiente paso de la trayectoria, esto es, observar los resultados de inserción laboral pero esta vez observándolo específicamente por titulación.

Es en ese sentido que formulamos las siguientes hipótesis:

a. Entre los titulados ocupados a tiempo completo $(\mathrm{n}=8.787)$, cuando tomamos en cuenta la titulación universitaria el peso del origen social influye en la inserción laboral (medida ésta por el nivel de ingresos obtenido en su ocupación).

b. Los graduados universitarios provenientes de orígenes sociales más desfavorecidos se encuentran más desocupados y más inactivos. Esto significaría que los titulados de orígenes más altos tienen más probabilidad de estar ocupados.

\section{Procedimiento}

Se realizó en primer lugar un análisis de tablas de contingencia con el fin de observar el nivel de asociación entre las variables cualitativas intervinientes en el análisis y la variable independiente. Para conocer el grado de asociación global de las variables se deben cumplir dos condiciones básicas: a) que haya menos del $20 \%$ de casillas con frecuencia esperada menor a 5 y por otro lado, que el test del estadístico Chi cuadrado sea inferior a 0,05 . Una vez corroborada la asociación se observa su fuerza a través del estadístico $\mathrm{V}$ de Cramer. Esta técnica se utilizó para corroborar las dos hipótesis.

En segundo lugar, como análisis explicativo se utiliza la regresión logística binaria, que permite analizar una variable dependiente $Y i$ que incluye dos alternativas excluyentes en términos de probabilidades (en nuestro caso ingresos altos o bajos), a partir de las variables independientes. La regresión logística permite pronosticar la pertinencia al grupo a partir de una variable dependiente o categórica cualitativa que en el caso particular de la binaria incluye dos valores (LópezRoldán y Fachelli, 2015). Se sigue luego una estrategia de modelización sustantiva (Jovell, 1995), es decir, se incluye en el modelo 
aquellas variables que se consideran pertinentes para explicar el fenómeno en nuestro caso Nivel ocupacional familiar (NOF) y Nivel formativo familiar (NFF). La especificación empírica de la primera hipótesis utilizando el modelo logístico se puede expresar como:

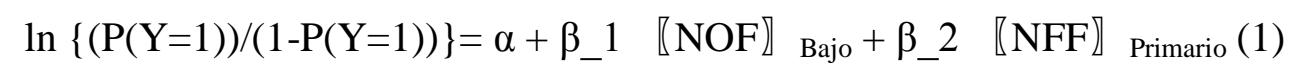

donde $\mathrm{P}$ es la probabilidad de tener ingresos altos.

Las variables dependientes utilizadas para probar las dos hipótesis se describen a continuación:

- Ingresos anuales brutos bajos o altos: Para el análisis de los ingresos entre los titulados ocupados, se efectuó una recodificación de la variable ingresos que originalmente estaba medida en rangos. Los diferenciamos en dos categorías: ingresos bajos e ingresos altos. El límite para determinar el tipo de ingresos se fijó en 24 mil euros anuales brutos. A continuación se muestra la variable original (tabla 1) y el resultado de la recodificación (tabla 2 ).

Tabla 1 - Ingresos anuales brutos

\begin{tabular}{cccc}
\hline & & Frecuencia & Porcentaje válido \\
\hline \multirow{4}{*}{ Válidos } & $1<9$ mil $€$ & 89 & 1,1 \\
& $29-12$ mil $€$ & 291 & 3,5 \\
& $312-15$ mil $€$ & 639 & 7,8 \\
& $415-18$ mil $€$ & 799 & 9,7 \\
& $518-24$ mil $€$ & 2699 & 32,7 \\
& $624-30$ mil $€$ & 2041 & 24,8 \\
& $730-40$ mil $€$ & 1225 & 14,9 \\
& $8>40$ mil $€$ & 462 & 5,6 \\
& Total & 8245 & 100,0 \\
& Sistema & 542 & \\
& & 8787 &
\end{tabular}

La siguiente tabla presenta la ingresos bajos y el 45,2 en el que posee recodificación de los ingresos, quedando el ingresos altos. $54,8 \%$ en el grupo de los graduados que tienen

Tabla 2 - Recodificación de ingresos

\begin{tabular}{llcc}
\hline & & Frecuencia & Porcentaje válido \\
\hline Válidos & 0 Bajos & 4517 & 54,8 \\
& 1 Altos & 3728 & 45,2 \\
& Total & 8245 & 100,0 \\
Perdidos & Sistema & 542 & \\
Total & & 8787 & \\
\hline
\end{tabular}

Fuente: elaboración propia sobre AQU Catalunya 2011

- Situación ocupacional:

Para probar la primera hipótesis, se dividió a los titulados según la actividad principal que realizaban cuatro años después de haber obtenido el grado: estar trabajando (ocupados), parados (sin trabajar y buscando trabajo), o inactivos (sin trabajar ni buscando trabajo). La encuesta indica que en 2011 el 88,6\% de los titulados de universidades públicas se encontraban ocupados, $7,8 \%$ en paro $\mathrm{y}$ $3,6 \%$ inactivos. 


\section{- Variables independientes: nivel ocupacional familiar y nivel formativo familiar}

El origen social de los titulados está medido a través de dos variables: el nivel ocupacional familiar (NOF) y el nivel formativo familiar (NFF). Para cada variable se utilizó una división en tres categorías (alta, media y baja), que da cuenta del máximo nivel alcanzado por cualquiera de los dos padres.

\section{- Nivel ocupacional familiar (NOF)}

Con respecto al NOF, la categoría baja corresponde a padres que trabajan por cuenta ajena en ocupaciones no cualificadas, así como a autónomos cuyas funciones no requieren educación superior; la categoría media incluye a los padres empleados con funciones cualificadas; mientras que la categoría alta comprende a los padres que trabajan por cuenta propia con funciones de dirección o de técnico superior, así como a los autónomos que desempeñan funciones de nivel universitario (Planas y Fachelli, 2010).

\section{- Nivel formativo familiar (NFF)}

En el caso del NFF, la categoría baja se compone de uno o ambos padres con nivel educativo hasta primario, la categoría media se caracteriza por comprender a uno o ambos padres con estudios medios, y la tercera reúne uno o ambos padres con educación superior.

Para analizar la asociación entre el origen social y los resultados de inserción laboral en primer lugar se realizaron tablas de contingencia para cada titulación. Seguidamente se aplicó la regresión logística binomial simple a las 116 titulaciones y se presentan en este artículo sólo los resultados de aquellas titulaciones que cumplen las condiciones de aplicación estadística, tal como se explicará oportunamente.

Este procedimiento es muy relevante, pues delimita el ámbito sobre qué carreras se puede tener conocimiento o dar respuesta a nuestra pregunta de investigación y sobre cuáles no. Este es un proceso de indagación que ha venido abordándose desde el ámbito general (todos los graduados catalanes en forma agrupada, referenciados en la introducción en trabajos previos) hasta el grado de detalle más minucioso, del que pretendemos dar cuenta en este artículo. El interés del análisis minucioso tiene mucha importancia porque discrimina entre las carreras que pueden analizarse y las que no. Sobre las primeras se sacan resultados fidedignos y se identifica el grupo de las segundas, sobre las cuales no se puede responder la pregunta.

\section{Resultados}

Análisis de la relación entre ingresos y origen social: tablas de contingencia

El primer análisis consiste en la elaboración de tablas de contingencia para observar la relación entre el origen social y los ingresos al interior de cada titulación, mediante el estadístico Chi cuadrado. Se elaboraron 119 tablas de contingencia para cada indicador de origen social, una por cada titulación e indicador de origen social, en total 238 tablas de contingencia. Los pasos dados para realizar este análisis se presentan a continuación:

1) Discriminar entre aquellas titulaciones en las que se cumplen los requisitos para analizar las tablas, es decir, que tienen un porcentaje menor a $20 \%$ en las casillas con una frecuencia esperada menor a 5 , tal como se recomienda en la aplicación de esta técnica.

2) Determinar aquellas titulaciones que muestran una relación estadísticamente significativa, con un nivel de confianza (NC) de 95\%, es decir, con una p $<0,05$ en el estadístico Chi cuadrado.

3) Se seleccionan aquellas titulaciones con resultados significativos y se procede a analizar el sentido de la relación entre nivel de ingresos y origen social.

- Nivel ocupacional familiar (NOF)

En la figura 1 se representan dos ejes, estos son: si cumplen los requisitos para analizar las tablas $(<20 \%$ de casillas con frecuencia esperada menor a 5) o no (eje vertical) y si su 
nivel de asociación es estadísticamente significativo $(\mathrm{p}<0,05)$ o no (eje horizontal). De este cruce surgen cuatro contenidos distintos y se representan las titulaciones que pueden enmarcarse en cada uno de ellos.

Como puede observarse en la parte superior del cuadro, del total de titulaciones que cumple con un número suficiente de casos para analizar las tablas de contingencia (49), únicamente en cinco titulaciones se observa una relación estadística significativa entre el nivel ocupacional familiar y los ingresos (cuadrante superior derecho), mientras que en las 44 titulaciones restantes, los ingresos bajos y altos se distribuyen de manera homogénea entre los tres niveles ocupacionales de las familias (cuadrante superior izquierdo).

Figura 1: Síntesis tablas de contingencia, ingresos y nivel ocupacional familiar (NOF)

\begin{tabular}{|c|c|c|c|}
\hline \multicolumn{4}{|c|}{ Cumple condición: Menos del $20 \%$ casillas con frecuencia esperada menor a 5} \\
\hline & D. Relaciones Laborales & D. Ciencias Empresariales & \multirow{7}{*}{$\begin{array}{c}\mathbf{P}<\mathbf{0 , 0 5} \\
\quad \text { Sig. }\end{array}$} \\
\hline & D. Trabajo Social & D. Educación Social & \\
\hline & L. Ciencias del Trabajo & L. Filología Inglesa & \\
\hline & D. Gestión y Administración Pública & L. Criminología & \\
\hline & L. Sociología & L. Actividad Física y del Deporte & \\
\hline$P=>0,05$ & $(\ldots \text { total } 44)^{* *}$ & & \\
\hline \multirow[t]{8}{*}{ No Sig. } & L. Geografía & L. Estudios Asia Oriental & \\
\hline & L. Historia del Arte & L. Humanidades & \\
\hline & L. Historia y Ciencias de la Música & L. Ciencias Actuariales y Financieras & \\
\hline & L. Filosofía & IT. Telecomunicaciones & \\
\hline & L. Lingüística & IT. Forestal (Explotaciones Forestales) & \\
\hline & L. Teoría de la Literatura & IT. Aeronáutica (Aeronavegación) & \\
\hline & $(\ldots \text { total } 54)^{* *}$ & & \\
\hline & \multicolumn{3}{|c|}{ No cumple condición: Más del $20 \%$ casillas con frecuencia esperada menor a 5} \\
\hline
\end{tabular}

Fuente: elaboración propia sobre AQU Catalunya 2011. D = Diplomatura; L = Licenciatura; IT = Ingeniería Técnica. ${ }^{* *}$ El listado completo de titulaciones aparece en el anexo 1.

Por otro lado, hay un total de 60 titulaciones en las que, por el escaso número de casos, no es posible extraer resultados válidos sobre la influencia del origen social ocupacional en la inserción laboral (parte inferior del cuadro). Sin embargo, este es un resultado importante, pues delimita la situación de las titulaciones sobre las cuales no se puede decir nada.

Entre las cinco titulaciones con resultados válidos y estadísticamente significativos ubicadas en el cuadrante superior derecho, cuatro pertenecen al área de ciencias sociales y una al área de humanidades, la relación entre nivel ocupacional de los padres e ingresos de los titulados se observa de la siguiente manera:

o D. Ciencias Empresariales $(p=0,012 ; \mathrm{V}$ de Cramer $=0,15 ; n=386)$ : los ingresos bajos están relacionados con los orígenes ocupacionales bajos, los ingresos altos con los orígenes altos o medios (Anexo 1, Tabla 8). o L. Filología Inglesa $(\mathrm{p}=0,019 ; \mathrm{V}$ de Cramer $=0,32 ; n=75)$ : La relación es significativa sobre todo por la sobrerrepresentación del nivel ocupacional medio entre los que tienen ingresos bajos (Anexo 1, Tabla 7).

o D. Educación Social ( $\mathrm{p}=0,008 ; \mathrm{V}$ de Cramer $=0,27 ; n=133)$ : los ingresos bajos están relacionados con los orígenes ocupacionales bajos, los ingresos altos con los orígenes altos o medios (Anexo 1, Tabla 11).

o L. Criminología ( $\mathrm{p}=0,007 ; \mathrm{V}$ de Cramer $=0,33 ; n=88)$ : La relación es inversa a lo esperado. El origen ocupacional alto está relacionado con ingresos bajos $y$ viceversa.

o L. Ciencias de la Actividad Física y del Deporte $(p=0,009$; $\mathrm{V}$ de Cramer $=0,34$; $\mathrm{n}=$ 80): los ingresos bajos están relacionados con el nivel ocupacional bajo $\mathrm{y}$ alto, mientras que los ingresos altos 
sobre todo se relacionan con el nivel ocupacional medio (Anexo 1, Tabla 12).

\section{- Nivel formativo familiar (NFF)}

Siguiendo la misma lógica de lo presentado con respecto al nivel ocupacional, en la figura 2 se presenta un listado de las titulaciones, en función de dos ejes: si cumplen los requisitos para analizar las tablas $(<20 \%$ casillas con frecuencia esperada menor a 5) y si tienen un resultado estadísticamente significativo $(p<0,05)$.

Entre las titulaciones con un número suficiente de casos para analizar las tablas de contingencia (49), únicamente en tres titulaciones se observa una relación estadística significativa entre el nivel formativo familiar y los ingresos, mientras que en las 46 titulaciones restantes los ingresos bajos y altos se distribuyen de manera homogénea entre los tres niveles formativos de las familias.

Con respecto a las titulaciones que se encuentran en los cuadrantes inferiores, un total de 59, no es posible extraer resultados válidos por el escaso número de casos sobre la influencia del origen formativo familiar en la inserción laboral. Sin embargo, como ya se ha señalado este es un resultado importante, pues delimita la situación de las titulaciones sobre las cuales no se puede decir nada respecto a este tipo de influencia.

Entre las tres titulaciones con resultados válidos y estadísticamente significativos, todas pertenecientes al área de ciencias sociales, la relación entre nivel formativo de los padres e ingresos de los titulados arroja las siguientes asociaciones:

o L. Criminología ( $\mathrm{p}=0,018$; $\mathrm{V}$ de Cramer $=0,30 ; n=88)$ : La relación es inversa a lo esperado. El nivel formativo superior está relacionado con ingresos bajos $\mathrm{y}$ viceversa. (Anexo 1, Tabla 15).

o L. CC. Políticas y de la Adm. ( $p=0,010$; $\mathrm{V}$ de Cramer $=0,32 ; \mathrm{n}=91$ ): de forma parecida al caso anterior, los ingresos bajos están relacionados con el nivel formativo superior, mientras que los ingresos altos están relacionados con el nivel formativo primario. (Anexo 1, Tabla 16).

o D. Educación Social $(\mathrm{p}=0,043 ; \mathrm{V}$ de Cramer $=0,22 ; n=135)$ : los ingresos bajos están relacionados con el nivel formativo primario, los ingresos altos con los del nivel formativo superior (Anexo 1, Tabla 18).

Figura 2 - Síntesis tablas de contingencia, ingresos y nivel formativo familiar

\begin{tabular}{|c|c|c|c|}
\hline & Menos del $20 \%$ casillas co & ncia esperada menor a 5 & \\
\hline & L. Antropología Social y Cultural & L. Criminología & \\
\hline & L. Historia & L. C. Políticas y de la Admón. & \\
\hline & L. ADE & D. Educación Social & \\
\hline & L. Economía & & \\
\hline & D. Investigación y Técnicas de Mercado & & \\
\hline$P>=0,05$ & $(\ldots \text { total } 46)^{* *}$ & & $P<0,05$ \\
\hline & L. Geografía & L. Filología Alemana & \\
\hline & L. Historia del Arte & IT. Agrícola (I. Agrarias y Alim) & \\
\hline & L. Historia y Ciencias de la Música & & \\
\hline & L. Filosofía & & \\
\hline & L. Lingüística & & \\
\hline & L. Teoría de la Literatura & & \\
\hline & $(\ldots \text { total } 57)^{* *}$ & & \\
\hline & Más del $20 \%$ casillas col & ncia esperada menor a 5 & \\
\hline
\end{tabular}


Balance entre los dos indicadores de origen social

Después de haber analizado de manera independiente cada indicador de origen social, se procedió a definir aquellas titulaciones que se relacionan con los dos indicadores (origen ocupacional y origen educativo) para ponerlo en relación con la inserción laboral de los graduados, medida ésta a través de sus ingresos. De esta manera hay titulaciones que no han superado la prueba, sea porque no cumplen las condiciones 0 porque cumpliéndolas no reflejan asociación entre las variables.

Así, de las 6 carreras que superaron todas las pruebas, 3 presentan influencia del origen ocupacional de los padres (cuadrante superior izquierdo), en una se detecta influencia del nivel educativo (cuadrante inferior derecho) y dos presentan una influencia de los dos indicadores de origen social: Criminología y Educación Social. En la figura 3 se sintetizan estos resultados y en el Anexo 3 se presentan todas las titulaciones.

Figura 3 - Balance entre el nivel ocupacional y el nivel formativo

\begin{tabular}{|c|c|c|c|}
\hline \multicolumn{4}{|c|}{ Hay relación con nivel ocupacional de los padres } \\
\hline & D. Ciencias Empresariales & D. Educación Social & \\
\hline \multirow{8}{*}{$\begin{array}{l}\text { No se pudo } \\
\text { determinar } \\
\text { relación con } \\
\text { nivel formativo } \\
\text { de los padres }\end{array}$} & L. Filología Inglesa & L. Criminología & \multirow{7}{*}{$\begin{array}{l}\text { Hay relación } \\
\text { con nivel } \\
\text { formativo de } \\
\text { los padres }\end{array}$} \\
\hline & L. Deporte & & \\
\hline & D. Relaciones Laborales & \multirow{5}{*}{$\begin{array}{l}\text { L. Ciencias Políticas } \\
\text { L. Ciencias Políticas }\end{array}$} & \\
\hline & $\begin{array}{l}\text { D. Trabajo Social } \\
\text { L. Ciencias del Trabajo }\end{array}$ & & \\
\hline & D. Gestión y Admón. Pública & & \\
\hline & L. Sociología & & \\
\hline & $(\ldots \text { total } 44)^{* *}$ & & \\
\hline & \multicolumn{3}{|c|}{ No se pudo determinar relación con nivel ocupacional de los padres } \\
\hline
\end{tabular}

Fuente: elaboración propia sobre AQU Catalunya 2011. D = Diplomatura; $L=$ Licenciatura ** El listado completo de titulaciones aparece en el anexo 3.

Análisis de la relación entre la situación laboral y el origen social

A la luz de los resultados obtenidos en el apartado anterior se explora la segunda hipótesis. El presupuesto es que si en la mayor parte de los casos que se pueden analizar no se encuentra influencia del origen social en la inserción laboral, entonces quiere decir que aún persiste la esperanza de encontrarlos en aquellos que están expulsados del mercado de trabajo (graduados en paro) o que se encuentran fuera de él porque están dedicándose a otras actividades (graduados inactivos). Así, en el segundo análisis se utiliza la variable dependiente "situación laboral” y se analiza su relación con las dos variables independientes de origen social. 
Tabla 3 - Asociación entre el Nivel ocupacional familiar (NOF) y la situación laboral de los titulados

\begin{tabular}{lllll}
\hline \multirow{2}{*}{ Situación laboral titulados } & \multicolumn{4}{c}{ Nivel ocupacional familiar (NOF) } \\
\cline { 2 - 5 } Ocupado & Alto & Medio & Bajo & Total \\
\hline \% columna & 4323 & 2987 & 3363 & 10673 \\
Resid. Corregidos & 88,6 & 88,7 & 88,6 & 88,6 \\
\hline Parado & $-0,2$ & 0,2 & $-0,1$ & \\
\% columna & 376 & 271 & 292 & 939 \\
Resid. Corregidos & 7,7 & 8,1 & 7,7 & 7,8 \\
\hline Inactivo & $-0,3$ & 0,6 & $-0,3$ & \\
\% columna & 181 & 108 & 140 & 429 \\
Resid. Corregidos & 3,7 & 3,2 & 3,7 & 3,6 \\
\hline Total & 0,7 & $-1,3$ & 0,5 & \\
\hline
\end{tabular}

Chi cuadrado $=0,729$

Fuente: elaboración propia sobre AQU Catalunya 2011

En primer lugar, cuando se analiza la relación entre el nivel ocupacional de los padres y la situación laboral de los titulados es decir si se encontraban trabajando, parados o inactivos- (tabla 3), los resultados no nos permiten afirmar que haya diferencias significativas según el nivel ocupacional de sus padres. Todos los graduados tienen probabilidades similares (no diferenciadas por origen) cuando se analiza la situación de ocupación, paro o inactividad.

Tabla 4 - Asociación entre en nivel formativo familiar (NFF) y la situación laboral de los graduados

\begin{tabular}{lllll}
\hline & \multicolumn{4}{c}{ Nivel formativo familiar (NFF) } \\
\cline { 2 - 5 } Situación laboral titulados & Bajo & Medio & Alto & Total \\
\hline Ocupado & 3965 & 3295 & 3527 & 10787 \\
\% columna & 89,2 & 89,5 & 87,2 & 88,6 \\
Resid. Corregidos & 1,6 & 2,0 & $-3,5$ & \\
\hline Parado & 332 & 263 & 357 & 952 \\
\% columna & 7,5 & 7,1 & 8,8 & 7,8 \\
Resid. Corregidos & $-1,1$ & $-1,8$ & 2,9 & \\
\hline Inactivo & 148 & 125 & 162 & 435 \\
\% columna & 3,3 & 3,4 & 4,0 & 3,6 \\
Resid. Corregidos & $-1,1$ & $-0,7$ & 1,8 & \\
\hline Total & 4445 & 3683 & 4046 & 12174 \\
\hline
\end{tabular}

Chi cuadrado =0,013; $V$ de Cramer $=0,023$

Fuente: elaboración propia sobre AQU Catalunya 2011

En segundo lugar, en la tabla 4 se observa una cierta influencia cultural de los padres en la situación laboral de los hijos. Es decir, el nivel formativo de los padres tiene un nivel de asociación con la situación laboral de sus hijos, aunque muy débil (con una fuerza del 2,3\%). Analicemos entonces esta influencia. Los residuos corregidos nos informan qué casillas explican el nivel de asociación (los residuos significativos superan el valor absoluto 1,96), en este caso los ocupados y parados provenientes de padres de estratos altos. El signo de los residuos marca la dirección de la asociación, así, los hijos de padres con nivel ocupacional alto están menos ocupados (residuo: -3,5) que el resto de los graduados y están más parados los hijos provenientes de estratos altos que el resto de los titulados (residuo: 2,9).

Como conclusión debemos rechazar la hipótesis 2 porque el origen ocupacional de los padres no influye en la situación laboral de sus hijos en cuanto a que algunos estén más parados que otros o con mayor inactividad, y porque el nivel formativo familiar que sí influye (aunque muy débilmente) lo hace en el 
sentido contrario al esperado: están más parados los hijos provenientes de sectores con mayor nivel formativo familiar y están tan inactivos unos como otros, pues no se observan diferencias significativas entre los tres grupos.

Análisis de la relación entre nivel de ingresos y el origen social: regresión logística binomial

Después de haber realizado las tablas de contingencia, se procede a realizar una serie de modelos logísticos para medir la influencia del origen social en los ingresos controlando por titulación. Para cada titulación se elaboró un modelo logístico introduciendo como variables independientes los dos indicadores de origen, de manera que se pudiera medir la influencia de cada uno de ellos sobre la variable dependiente: ingresos (la misma variable dicotómica utilizada en la sección 3.1 [2]

Una vez aplicadas las regresiones, se procedió a identificar aquellos modelos en los que los datos mostraban una bondad de ajuste significativa. De las 119 titulaciones analizadas, únicamente en seis titulaciones encontramos resultados estadísticamente significativos. En la tabla 5 se muestran los resultados de los modelos logísticos: el test de Hosmer y Lemeshow, el $\mathrm{R}^{2}$ de Nagelkerke, así como los casos válidos.

Tabla 5 - Resultados de las regresiones logísticas

\begin{tabular}{|c|c|c|c|c|}
\hline & \multirow[b]{2}{*}{$\mathrm{N}$} & \multirow[b]{2}{*}{$\mathrm{R}^{2}$ Nagelkerke } & \multicolumn{2}{|c|}{ Test Hosmer y Lemeshow } \\
\hline & & & Chi cuadrado & Sig. \\
\hline L. Filología Inglesa & 75 & ,219 & 2,426 & 877 \\
\hline D. Ciencias empresariales & 384 & 036 & 2,859 & ,722 \\
\hline L. Criminología & 88 & , 165 & 3,113 & ,539 \\
\hline L. Sociología & 69 & , 190 & 2,288 & ,891 \\
\hline D. Educación social & 133 & ,116 & ,425 & ,995 \\
\hline L. Actividad física y deporte & 80 & ,222 & 1,417 & ,841 \\
\hline
\end{tabular}

Fuente: elaboración propia sobre AQU Catalunya 2011

Cuando los casos son pocos como los que tenemos en la primera columna de la tabla 5 es conveniente aplicar el test de Hosmer y Lemeshow que nos indica si la regresión logística puede ser interpretada. La significatividad del estadístico igual o superior a 0,05 indica que efectivamente podemos aceptar los resultados de la regresión. A partir de esta comprobación podemos leer el $\mathrm{R}^{2}$ de Nagelkerke que nos informa sobre la bondad de ajuste del modelo. En este caso las titulaciones con mayor capacidad explicativa son L. Actividad física y deporte con el 22,2\%; L. Filología Inglesa con el 21,9\%, le siguen L. Sociología con el 19\%; L. Criminología con el $16,5 \%$ y D. Educación social con el 11,6\%. D. Ciencias Empresariales tiene muy baja capacidad explicativa (3,6\%).

En la tabla 6 se presentan los resultados de las regresiones logísticas. En todos los casos las categorías de referencia fueron los niveles de origen social más bajo, es decir, nivel ocupacional bajo y nivel formativo primario. 
Tabla 6 - Coeficientes de las regresiones logísticas

\begin{tabular}{|c|c|c|c|c|c|c|c|}
\hline & & B & E.T. & Wald & gl & Sig. & $\operatorname{Exp}(B)$ \\
\hline \multirow{7}{*}{ Filología Inglesa } & NOF (ref. bajo) & & & 5,969 & 2 & ,051 & \\
\hline & NOF (alto) &,- 210 & 792 & ,070 & 1 & 791 & 811 \\
\hline & NOF (medio) & $-2,702$ & 1,120 & 5,822 & 1 & ,016 & ,067 \\
\hline & NFF (ref. primario) & & & 2,558 & 2 & ,278 & \\
\hline & NFF(superior) &,- 042 & 948 & ,002 & 1 & 965 & 959 \\
\hline & NFF(medio) & ,929 & 705 & 1,737 & 1 & 187 & 2,533 \\
\hline & Constante &,- 738 & 432 & 2,920 & 1 & ,087 & 478 \\
\hline \multirow{7}{*}{$\begin{array}{l}\text { D. } \\
\text { empresariales }\end{array}$} & NOF (ref. bajo) & & & 4,876 & 2 & ,087 & \\
\hline & NOF (alto) & 602 & 293 & 4,228 & 1 & ,040 & 1,826 \\
\hline & NOF (medio) & ,440 & 269 & 2,671 & 1 & 102 & 1,552 \\
\hline & ${ }^{15}$ NFF (ref. primario) & & & 1,568 & 2 & 457 & \\
\hline & NFF(superior) & 288 & 332 & 753 & 1 & 385 & 1,334 \\
\hline & NFF(medio) & 290 & 248 & 1,364 & 1 & 243 & 1,336 \\
\hline & Constante & $-1,051$ & ,194 & 29,299 & 1 & ,000 & ,350 \\
\hline \multirow{7}{*}{ L. Criminología } & NOF (ref. bajo) & & & 3,449 & 2 & ,178 & \\
\hline & NOF (alto) & $-1,275$ & 687 & 3,447 & 1 & ,063 & 279 \\
\hline & NOF (medio) &,- 399 & 563 & 502 & 1 & 479 & 671 \\
\hline & NFF (ref. primario) & & & 1,558 & 2 & 459 & \\
\hline & NFF(superior) &,- 829 & 666 & 1,553 & 1 & 213 & 436 \\
\hline & NFF(medio) &,- 248 & ,593 & , 175 & 1 & 676 & 780 \\
\hline & Constante & 1,229 & ,419 & 8,602 & 1 & ,003 & 3,417 \\
\hline \multirow{7}{*}{ L. Sociología } & NOF (ref. bajo) & & & 5,510 & 2 & ,064 & \\
\hline & NOF (alto) & $-1,476$ & 818 & 3,260 & 1 & ,071 & 228 \\
\hline & NOF (medio) & ,057 & 734 & 006 & 1 & 939 & 1,058 \\
\hline & NFF (ref. primario) & & & 4,230 & 2 & 121 & \\
\hline & NFF(superior) & ,009 & ,715 & ,000 & 1 & 990 & 1,009 \\
\hline & NFF(medio) & $-1,400$ & ,764 & 3,355 & 1 & ,067 & 247 \\
\hline & Constante & ,379 & ,615 & ,380 & 1 & ,538 & 1,461 \\
\hline \multirow{7}{*}{ D. Educación social } & NOF (ref. bajo) & & & 4,470 & 2 & 107 & \\
\hline & NOF (alto) & 1,418 & 671 & 4,457 & 1 & ,035 & 4,127 \\
\hline & NOF (medio) & 927 & 664 & 1,951 & 1 & 162 & 2,527 \\
\hline & NFF (ref. primario) & & & 416 & 2 & 812 & \\
\hline & NFF(superior) & ,418 & 652 & 411 & 1 & ,521 & 1,520 \\
\hline & NFF(medio) & 148 & ,561 & ,069 & 1 & 792 & 1,159 \\
\hline & Constante & $-2,259$ & 488 & 21,387 & 1 & ,000 & 104 \\
\hline \multirow{7}{*}{$\begin{array}{l}\text { L. Actividad física } \\
\text { deporte }\end{array}$} & NOF (ref. bajo) & & & 9,545 & 2 & ,008 & \\
\hline & NOF (alto) & 1,901 & 948 & 4,016 & 1 & ,045 & 6,690 \\
\hline & NOF (medio) & 2,606 & 843 & 9,544 & 1 & ,002 & 13,540 \\
\hline & ${ }^{\mathrm{y}}$ NFF (ref. primario) & & & 4,009 & 2 & 135 & \\
\hline & NFF(superior) & $-1,409$ & 864 & 2,660 & 1 & 103 & 244 \\
\hline & NFF(medio) &,- 281 & ,878 & 103, & 1 & 749 & 755 \\
\hline & Constante & $-1,869$ & 642 & 8,488 & 1 & ,004 & 154 \\
\hline
\end{tabular}

Fuente: elaboración propia sobre AQU Catalunya 2011

Tomando en cuenta la significación de la variable, solo la Licenciatura en Actividad Física y Ciencias del Deporte, el nivel ocupacional alto mostró una influencia estadísticamente significativa del origen social $(\mathrm{p}=0,008)$. Aquí, los titulados cuyos padres tenían un nivel ocupacional alto o medio, mostraron entre $6 \quad$ y 13 veces más posibilidades de tener ingresos más altos que aquellos cuyos padres tenían un nivel ocupacional bajo.

En el resto de modelos, ninguna variable mostró resultados estadísticamente 
significativos, aunque en algunas de las categorías sí fue posible encontrarlos:

o L. Filología inglesa: los hijos de padres con nivel ocupacional medio tienen menores posibilidades de tener ingresos altos que los del nivel bajo $(\operatorname{Exp}(B)=0,67)$.

o D. Ciencias empresariales: los hijos de padres con nivel ocupacional alto tienen casi el doble de posibilidades de tener ingresos altos que el nivel bajo $(\operatorname{Exp}(B)=1,82)$.

o D. Educación social: los provenientes de nivel ocupacional alto tienen 4 veces más posibilidades de tener ingresos altos que los que provienen de hogares con nivel ocupacional bajo $(\operatorname{Exp}(B)=4,127)$.

\section{Conclusiones y discusión}

Han sido distintas las aproximaciones que hemos realizado para analizar la influencia del origen social en la inserción laboral temprana de los graduados universitarios. En trabajos anteriores pudimos advertir -para el conjunto de los graduados en el curso 2003-2004 y entrevistados en 2008- una influencia débil del origen social que apenas nos permitía destacar algunas carreras con resultados potentes como Historia del Arte, Filología inglesa, Bellas artes, Maestro de Educación Física y Técnicos industriales (Planas \& Fachelli, 2010).

La inclusión de las variables de origen social por primera vez en aquella encuesta (2008) fue repetida en la encuesta de 2011 que es la que utilizamos en este artículo, permitiendo así constatar que la mayor parte de los universitarios catalanes conforman la primera generación de su grupo familiar en asistir a la universidad. Este hecho nos habla de la expansión universitaria y también refleja la importancia de la descentralización de las universidades públicas a partir de los años ochenta. Esta situación ha generado que un número importante de personas sin recursos pudieran acceder a la universidad, dado que el costo de traslado a los centros urbanos con universidades, que en general no presentaba restricciones para los sectores medios y acomodados, eran una clara barrera al acceso para los sectores más bajos.

Tenemos bastante estudiado en el ámbito social la importancia del origen social como factor determinante para explicar las limitaciones de acceso a ciertas oportunidades que promueven el ascenso social. Con los graduados universitarios este tema no ha estado suficientemente estudiado y es en ese sentido que pretendemos aportar la mayor cantidad de evidencias posible para comenzar a discutir dos ideas que desde hace mucho tiempo están instaladas pero que se reavivan con la crisis económica actual: que la universidad es una fábrica de parados y que les va mucho mejor a los que provienen de familias acomodadas.

Particularmente nos hemos centrado en revisitar estos tópicos con una nueva fuente de datos (AQU, 2011) y en esta ocasión hemos bajado a la unidad de análisis más pequeña, que es la titulación. Esto después de haber estudiado el tema a niveles más agregados y con resultados que cuestionaban los tópicos habituales (Torrents \& Fachelli, 2015, Fachelli, Torrents \& Navarro-Cendejas, 2014, Fachelli \& Planas, 2014, Fachelli \& Planas, 2011). Claro está que bajar a este nivel de detalle tiene un costo alto, muchas asociaciones no tienen significatividad estadística. Y esto es así a pesar de que la muestra ha sido diseñada para poder analizar los datos por titulación. Pero depende de la distribución de las frecuencias que se dé en cada categoría de una variable y la cantidad de variables a tomar en cuenta, que se llegue con éxito a analizarlas efectivamente.

Los resultados que ofrecemos en este artículo son menos de los que esperábamos presentar inicialmente (119 titulaciones) pero son aquellos sobre los cuales se puede decir algo con un respetable nivel de confianza. Así, este trabajo aporta información o una respuesta para los expertos que pensaban que finalmente a este nivel iban a tener probada la tesis de reproducción social (entre quienes nos incluimos). No obstante constatar que no es 
posible afirmar un determinado comportamiento también es una respuesta.

Como síntesis y recuento de lo realizado debemos mencionar que para realizar esta tarea seguimos dos hipótesis, la primera afirmaba que el peso del origen social influye en la inserción laboral de los graduados universitarios si se analiza dicho origen por titulación. La segunda hipótesis abordaba a los titulados que quedan fuera de la primera, es decir, a los parados e inactivos. En ese sentido se postulaba que los universitarios provenientes de orígenes más bajos en términos ocupacionales y culturales se encontraban más desocupados y más inactivos.

$\mathrm{Al}$ revisar la primera hipótesis y en lo que respecta a los resultados obtenidos a través de las tablas de contingencia se puede destacar lo siguiente:

a) Con relación al origen a partir de la ocupación de los padres se pudo establecer que de las 49 titulaciones que cumplieron las condiciones de análisis sólo en 5 aparece la influencia del origen, a saber: D. Ciencias Empresariales; D. Educación Social; L. Filología Inglesa; L. Criminología y L. Actividad Física y del Deporte. No obstante, la relación de la asociación esperada por la hipótesis solo se da en las dos diplomaturas mencionadas inicialmente.

b) Por lo que hace a la influencia del origen analizado a partir del nivel formativo familiar se pudo establecer que de las 49 titulaciones que cumplen las condiciones para ser analizadas sólo en 3 aparece la influencia de los padres: L. Criminología; L. Ciencias Políticas y D. Educación Social. No obstante, la relación esperada según la hipótesis sólo se cumple en la Diplomatura de Educación Social ya que en Criminología y en Ciencias Políticas la relación es inversa, es decir ganan más los que provienen de orígenes más bajos. c) Cuando hacemos el balance y analizamos la intersección de estos grupos sólo podemos quedarnos con dos titulaciones que tienen influencia doble, es decir, tanto a nivel ocupacional como a nivel formativo familiar. $\mathrm{Y}$ en este caso debemos descartar una de ellas (Criminología) porque los resultados esperados sólo se cumplen en la Diplomatura de Educación Social.

Con respecto a la primera hipótesis y a partir de los resultados obtenidos a través de las regresiones logísticas se puede destacar lo siguiente:

a) De las 116 titulaciones analizadas sólo 6 superaron las restricciones estadísticas en todos los indicadores a tomar en cuenta en un análisis de este tipo, a saber: L. Filología Inglesa; D. Ciencias empresariales; L. Criminología; L. Sociología; D. Educación social y L. Actividad física y deporte.

b) Que de esas 6 titulaciones sólo una mostró un impacto significativo del origen ocupacional de los padres sobre el ingreso (L. Actividad física y deporte).

c) Que ninguna titulación mostró una influencia del nivel formativo familiar cuando se controla también por el nivel ocupacional de los padres.

Sobre la segunda hipótesis los resultados encontrados son los siguientes:

a) No se observa influencia alguna del origen social estudiado a través del nivel ocupacional de los padres que permita diferenciar situaciones de ocupación, paro o inactividad de los graduados. Todos los graduados según su origen social están igualmente ocupados, parados o en la inactividad.

b) Se pudo observar influencia del origen social cuando se lo estudia a través del nivel formativo de los padres. Tanto los ocupados como los parados provienen de estratos culturales más altos. Si bien esta asociación se encontró en forma 
muy débil es sin embargo en el sentido opuesto al esperado, lo que nos lleva a pensar en la capacidad de espera de los hijos de estratos más altos en momentos de crisis en el mercado laboral, ya vislumbrado en trabajos anteriores.

Tomando en cuenta las dos hipótesis utilizadas como guía en esta investigación y a la luz de los resultados obtenidos nos vemos obligados a rechazarlas. Por lo tanto, aun controlando por titulación, no observamos efectos relevantes que nos lleven a creer que el origen social influye en la inserción laboral de la mayor parte de los titulados. La excepción que confirma la regla son los 133 titulados de la Diplomatura en Educación Social que mostraron ajustarse al comportamiento esperado, es decir, aquellos que provienen de orígenes altos tanto económico como cultural, perciban ingresos más altos.

Una reflexión general es que consideramos relevante sumar evidencias en este sentido y comenzar a interpelar nuestro propio imaginario a partir de evidencias objetivas. Es desde ese lugar en el que podemos sacar algunas conclusiones de política educativa. En estos días se discute una reforma educativa de reducción de los grados a tres años y la extensión de los Máster a dos. Esta reforma llega luego de una bastante reciente, la de Bolonia, que eliminó las Diplomaturas e instaló los grados de cuatro años. Los efectos de las políticas educativas pueden ser evaluados cuando pasa un tiempo prudencial. En este caso nosotros estamos aportando evidencias que preceden a la reforma que ahora se quiere realizar. En ese sentido y desde la perspectiva de inserción laboral el sistema de educación superior, ya reformado, no parece haber funcionado tan mal.

Queda entonces continuar el análisis con el objetivo de constatar si las siguientes cohortes graduadas en los años posteriores a este trabajo, también bajo la influencia de una crisis profunda, han tenido las mismas posibilidades. Esta es la tarea que emprenderemos próximamente.

\section{Referencias}

AQU Catalunya (2011). Universitat i treball a Catalunya 2011. Barcelona: Agència per a la Qualitat del Sistema Universitari de Catalunya.

Baudelot, C., Benoliel, R., Cukrowicz, H. \& Establet, R. (1981). Los estudiantes, el empleo y la crisis. Madrid: Akal.

Calmand, J., \& Epiphane, D. (2012). L'insertion professionnelle après des études supérieures: des diplômés plus égaux que d'autres.... Formation Emploi, 117, 11-28.

Carabaña, J. \& de la Fuente, G. (2015). Facultad por Facultad. Origen familiar y empleo de los licenciados en CCSS y Humanidades de la UCM en el año 2003. Revista Complutense de Educación, 26(3).

Fachelli, S. \& Planas, J. (2014). Inserción profesional y movilidad intergeneracional de los universitarios: de la expansión a la crisis. Revista Española de Sociología (RES), 21, 69-98. Disponible en http://ddd.uab.cat/pub/artpub/2014/125654/r evespsoc_a2014n21p69iSPA.pdf

Fachelli, S.; Torrents, D. \& Navarro-Cendejas, J. (2014). ¿La universidad española suaviza las diferencias de clase en la inserción laboral? Revista de Educación, 364, 119$144 . \quad$ Disponible en http://ddd.uab.cat/pub/artpub/2014/118532/r evedu_a2014m4-6n364p119iSPA.pdf

Gerber, T. P. \& Cheung, S. Y. (2008). Horizontal Stratification in Postsecondary Education: Forms, Explanations, and Implications. Annual Review of Sociology, 34(1), 299-318.

Jovell, A. (1995). Análisis de regresión logística. Cuadernos Metodológicos del CIS $\mathrm{N}^{\circ} 15$. Madrid.

López-Roldán, P. \& Fachelli, S. (2015). Metodología de la Investigación Social Cuantitativa. Bellaterra (Cerdanyola del Vallès): Dipòsit Digital de Documents, Universitat Auònoma de Barcelona. 
Lucas, S. (2001). Effectively maintained inequality: Education transitions, track mobility, and social background effects. American Journal of Sociology, 106(6), 1642-1690.

Navarro-Cendejas, J. (2013). Universidad y mercado de trabajo en Cataluña: un análisis de la inserción laboral de los titulados universitarios. Tesis doctoral. Universidad Autónoma de Barcelona. Disponible en http://ddd.uab.cat/pub/tesis/2014/hdl_10803 _134648/jnc1de1.pdf

Planas , J. \& Fachelli, S. (2010). Catalan universities as a factor of equity and professional mobility. Barcelona: Agència per a la Qualitatat del Sistema Universitari de Catalunya (AQU). Disponible en http://ddd.uab.cat/pub/llibres/2010/114675/c atunifacequ_a2010.pdf

Salas, M. (2005). La demanda de Educación Superior: un análisis microeconómico con datos de corte transversal. Revista de Educación, 337, 327-349.

Torrents, D. (2012). L'accés a la universitat a l'Estat espanyol al 2009: els condicionants d'accés. Universitat Autònoma de Barcelona.

Torrents, D. \& Fachelli S. (2015). El efecto del origen social con el paso del tiempo: la inserción laboral de los graduados universitarios españoles durante la democracia. Revista Complutense de Educación, 26(2), 331-349.

Triventi, M. (2013). Stratification in Higher Education and Its Relationship with Social Inequality: A Comparative Study of 11 European Countries. European Sociological Review, 29(3), 489-502.

Troiano, H. \& Elias, M. (2013). University access and after: explaining the social composition of degree programmes and the contrasting expectations of students. Higher
Education, 67(5), 637-654. DOI: http://doi.org/10.1007/s10734-013-9670-4

Van de Werfhorst, H. \& Luijkx, R. (2010). Educational Field of Study and Social Mobility: Disaggregating Social Origin and Education. Sociology, 44(4), 695-715.

\section{NOTAS}

${ }^{[1]}$ Las preguntas de la encuesta están disponibles en la página Web de la AQU: http://www.aqu.cat/doc/doc_21620985_1.pdf (Consulta 10/04/2014)

${ }^{[2]}$ En los Anexos 1 y 2 se pueden consultar las tablas de contingencia que miden de forma separada la asociación entre los ingresos de los titulados y las dos variables de origen social para cada una de las titulaciones que se presentan en esta sección.

\section{AGRADECIMIENTOS}

Los autores forman parte del GRET, Grup de Recerca Educación i Treball de la Universitat Autònoma de Barcelona. La versión escrita de este artículo ha sido discutida en el marco del "Estudi sobre l'equitat a l'accès i sortida de la formació universitària” financiada por AQU (2015). Por su parte, la ponencia que dio origen a este artículo tuvo lugar en el marco del Proyecto ITUNEQMO (CSO2010-19271), financiado por el "Plan Nacional de Investigación científica, desarrollo e investigación tecnológica" del Ministerio de Ciencia e Innovación. La Comisión de Seguimiento interna estuvo compuesta por Helena Troiano, Marina Elías y Joaquim Casal. La Comisión de Seguimiento externa del proyecto estuvo compuesta por Julio Carabaña, Marina Subirats, Jean-François Germe, Adrián Acosta y Néstor López. A todos ellos agradecemos los aportes realizados y su compromiso en todas las etapas del proyecto 


\section{ANEXOS}

1. Asociación entre ingresos del titulado y estatus laboral de los padres, titulaciones seleccionadas

Tabla 7 - Licenciatura en Filología Inglesa. Asociación entre ingresos y estatus laboral de los padres

\begin{tabular}{ccccc}
\hline & \multicolumn{4}{c}{ Nivel ocupacional familiar (NOF) } \\
\cline { 2 - 5 } Situación laboral titulados & Alto & Medio & Bajo & Total \\
\hline Ingresos bajos & 13 & 20 & 21 & 54 \\
\% columna & $65.0 \%$ & $95.2 \%$ & $61.8 \%$ & $72.0 \%$ \\
Resid. Corregidos & -.8 & 2.8 & -1.8 & \\
\hline Ingresos altos & 7 & 1 & 13 & 21 \\
$\%$ columna & $35.0 \%$ & $4.8 \%$ & $38.2 \%$ & $28.0 \%$ \\
Resid. Corregidos & .8 & -2.8 & 1.8 & \\
\hline Total & 20 & 21 & 34 & 75 \\
\hline
\end{tabular}

Chi cuadrado = 0,019. Fuente: elaboración propia sobre AQU Catalunya 2011.

Tabla 8 - Diplomatura en Ciencias Empresariales. Asociación entre ingresos y estatus laboral de los padres

\begin{tabular}{lrrrrr}
\hline & \multicolumn{5}{c}{ Nivel ocupacional familiar (NOF) } \\
\cline { 2 - 6 } Situación laboral titulados & Alto & \multicolumn{2}{c}{ Medio } & \multicolumn{1}{c}{ Bajo } & Total \\
\hline Ingresos bajos & 64 & 64 & 120 & 248 \\
& \% columna & $55.7 \%$ & $61.0 \%$ & $72.3 \%$ & $64.2 \%$ \\
\multicolumn{2}{c}{ Resid. Corregidos } & -2.3 & -.8 & 2.9 & \\
\hline Ingresos altos & 51 & 41 & 46 & 138 \\
& \% columna & $44.3 \%$ & $39.0 \%$ & $27.7 \%$ & $35.8 \%$ \\
& Resid. Corregidos & 2.3 & .8 & -2.9 & \\
\hline Total & & 115 & 105 & 166 & 386 \\
\hline
\end{tabular}

Chi cuadrado = 0,012. Fuente: elaboración propia sobre AQU Catalunya 2011.

Tabla 9 - Licenciatura en Criminología. Asociación entre ingresos y estatus laboral de los padres

\begin{tabular}{|c|c|c|c|c|}
\hline \multirow[b]{2}{*}{ Situación laboral titulados } & \multicolumn{4}{|c|}{ Nivel ocupacional familiar (NOF) } \\
\hline & Alto & Medio & Bajo & Total \\
\hline Ingresos bajos & 15 & 10 & 9 & 34 \\
\hline$\%$ columna & $65.2 \%$ & $34.5 \%$ & $25.0 \%$ & $38.6 \%$ \\
\hline Resid. Corregidos & 3.0 & -.6 & -2.2 & \\
\hline Ingresos altos & 8 & 19 & 27 & 54 \\
\hline \% columna & $34.8 \%$ & $65.5 \%$ & $75.0 \%$ & $61.4 \%$ \\
\hline Resid. Corregidos & -3.0 & .6 & 2.2 & \\
\hline Total & 23 & 29 & 36 & 88 \\
\hline
\end{tabular}

Chi cuadrado = 0,007. Fuente: elaboración propia sobre AQU Catalunya 2011.

Tabla 10 - Diplomatura en Educación Social. Asociación entre ingresos y estatus laboral de los padres

\begin{tabular}{|c|c|c|c|c|}
\hline \multirow[b]{2}{*}{ Situación laboral titulados } & \multicolumn{4}{|c|}{ Nivel ocupacional familiar (NOF) } \\
\hline & Alto & Medio & Bajo & Total \\
\hline Ingresos bajos & 30 & 27 & 46 & 103 \\
\hline \% columna & $63.8 \%$ & $77.1 \%$ & $90.2 \%$ & $77.4 \%$ \\
\hline Resid. Corregidos & -2.8 & .0 & 2.8 & \\
\hline Ingresos altos & 17 & $\overline{8}$ & 5 & 30 \\
\hline \% columna & $36.2 \%$ & $22.9 \%$ & $9.8 \%$ & $22.6 \%$ \\
\hline Resid. Corregidos & 2.8 & .0 & -2.8 & \\
\hline Total & 47 & 35 & 51 & 133 \\
\hline
\end{tabular}

Chi cuadrado = 0,008. Fuente: elaboración propia sobre AQU Catalunya 2011. 
Fachelli, Sandra \& Navarro-Cendejas, José (2015). Relación entre origen social e inserción laboral de los graduados universitarios. RELIEVE, 21 (2), art. 2. DOI: http://dx.doi.org/10.7203/relieve.21.2.7812

Tabla 11 - Licenciatura en Actividad Física y Deporte. Asociación entre ingresos y estatus laboral de los padres

\begin{tabular}{ccccc}
\hline & \multicolumn{4}{c}{ Nivel ocupacional familiar (NOF) } \\
\cline { 2 - 5 } Situación laboral titulados & Alto & Medio & Bajo & Total \\
\hline Ingresos bajos & 28 & 7 & 22 & 57 \\
$\%$ columna & $71.8 \%$ & $43.8 \%$ & $88.0 \%$ & $71.3 \%$ \\
Resid. Corregidos & .1 & -2.7 & 2.2 & \\
\hline Ingresos altos & 11 & 9 & 3 & 23 \\
$\%$ columna & $28.2 \%$ & $56.3 \%$ & $12.0 \%$ & \\
Resid. Corregidos & -.1 & 2.7 & -2.2 & 80 \\
\hline Total & 39 & 16 & 25 & \\
\hline
\end{tabular}

Chi cuadrado = 0,009. Fuente: elaboración propia sobre AQU Catalunya 2011.

2. Asociación entre ingresos del titulado y el nivel formativo de los padres, titulaciones $\underline{\text { seleccionadas }}$

Tabla 12 - Licenciatura en Criminología. Asociación entre ingresos y nivel formativo de los padres

\begin{tabular}{|c|c|c|c|c|}
\hline \multirow[b]{2}{*}{ Situación laboral titulados } & \multicolumn{4}{|c|}{ Nivel formativo familiar (NFF) } \\
\hline & Alto & Medio & Bajo & Total \\
\hline Ingresos bajos & 14 & 7 & 13 & 34 \\
\hline$\%$ columna & $63.6 \%$ & $35.0 \%$ & $28.3 \%$ & $38.6 \%$ \\
\hline Resid. Corregidos & 2.8 & -.4 & -2.1 & \\
\hline Ingresos altos & 8 & 13 & 33 & 54 \\
\hline$\%$ columna & $36.4 \%$ & $65.0 \%$ & $71.7 \%$ & $61.4 \%$ \\
\hline Resid. Corregidos & -2.8 & .4 & 2.1 & \\
\hline Total & 22 & 20 & 46 & 88 \\
\hline
\end{tabular}

Chi cuadrado = 0,018. Fuente: elaboración propia sobre AQU Catalunya 2011.

Tabla 13 - Licenciatura en Ciencias Políticas y de la Administración. Asociación entre ingresos y nivel formativo de los padres

\begin{tabular}{ccccc}
\hline & \multicolumn{4}{c}{ Nivel formativo familiar (NFF) } \\
\cline { 2 - 5 } Situación laboral titulados & Alto & Medio & Bajo & Total \\
\hline Ingresos bajos & 31 & 20 & 4 & 55 \\
$\%$ columna & $73.8 \%$ & $57.1 \%$ & $28.6 \%$ & $60.4 \%$ \\
Resid. Corregidos & 2.4 & -.5 & -2.7 & 36 \\
\hline Ingresos altos & 11 & 15 & 10 & $39.6 \%$ \\
\% columna & $26.2 \%$ & $42.9 \%$ & $71.4 \%$ & \\
Resid. Corregidos & -2.4 & .5 & 2.7 & 91 \\
\hline Total & 42 & 35 & 14 & \\
\hline
\end{tabular}

Chi cuadrado = 0,010. Fuente: elaboración propia sobre AQU Catalunya 2011.

Tabla 14 - Diplomatura en Educación Social. Asociación entre ingresos y nivel formativo de los padres

\begin{tabular}{ccccc}
\hline & \multicolumn{4}{c}{ Nivel formativo familiar (NFF) } \\
\cline { 2 - 5 } Situación laboral titulados & Alto & Medio & Bajo & Total \\
\hline Ingresos bajos & 18 & 34 & 53 & 105 \\
\% columna & $62.1 \%$ & $77.3 \%$ & $85.5 \%$ & $77.8 \%$ \\
Resid. Corregidos & -2.3 & -.1 & 2.0 & 30 \\
\hline Ingresos altos & 11 & 10 & 9 & $22.2 \%$ \\
$\%$ columna & $37.9 \%$ & $22.7 \%$ & $14.5 \%$ & \\
Resid. Corregidos & 2.3 & .1 & -2.0 & 135 \\
\hline Total & 29 & 44 & 62 & \\
\hline
\end{tabular}

Chi cuadrado = 0,043. Fuente: elaboración propia sobre AQU Catalunya 2011. 
Fachelli, Sandra \& Navarro-Cendejas, José (2015). Relación entre origen social e inserción laboral de los graduados universitarios. RELIEVE, 21 (2), art. 2. DOI: http://dx.doi.org/10.7203/relieve.21.2.7812

\section{Síntesis de tablas de contingencia, ingresos y nivel ocupacional familiar: listado completo de $\underline{\text { titulaciones }}$}

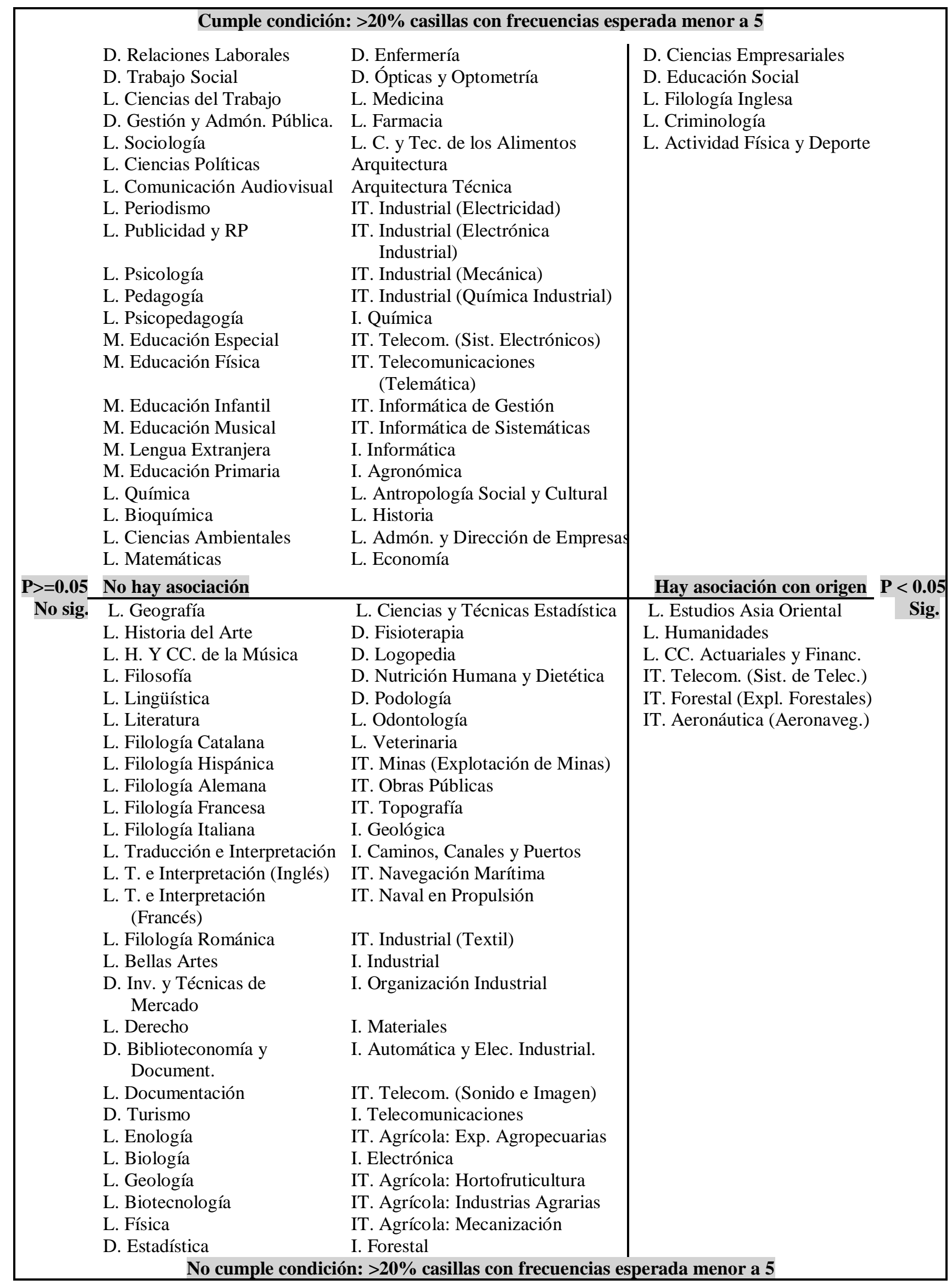


Fachelli, Sandra \& Navarro-Cendejas, José (2015). Relación entre origen social e inserción laboral de los graduados universitarios. RELIEVE, 21 (2), art. 2. DOI: http://dx.doi.org/10.7203/relieve.21.2.7812

4. Síntesis de tablas de contingencia, ingresos y nivel formativo familiar: listado completo de titulaciones

\section{Cumple condición: $>\mathbf{2 0} \%$ casillas con frecuencias esperada menor a $\mathbf{5}$}

L. Antropología Social y

Cultural

L. Historia

L. Adm. y Dirección de

Empresas

L. Economía

D. Inv. y Técnicas de Mercado

D. Ciencias Empresariales

L. Derecho

D. Relaciones Laborales

D. Trabajo Social

L. Ciencias del Trabajo

D. Gestión y Admón. Pública.

L. Sociología

L. Comunicación Audiovisual

L. Periodismo

L. Publicidad y RP

L. Psicología

L. Pedagogía

L. Psicopedagogía

M. Educación Especial

M. Educación Física

M. Educación Infantil

M. Educación Musical

M. Lengua Extranjera

$\mathbf{P}>=0.05$ No hay asociación

No sig. L. Geografía

L. Historia del Arte

L. H H $^{\mathrm{a}}$ CC. de la Música

L. Estudios Asia Oriental

L. Filosofía

L. Humanidades

L. Lingüística

L. T. Literaria y Literatura

L. Filología Catalana

L. Filología Hispánica

L. Filología Inglesa

L. Filología Francesa

L. Traducción e Interpretación

L. T. e Interpretación (Inglés)

L. T. e Interpretación (Francés)

L. Filología Románica

L. Bellas Artes

L. CC. Actuariales y Financ.

D. Biblioteconomía y

Documentación

L. Documentación

D. Turismo

L. Enología

L. Geología

L. Biotecnología

L. Física

D. Estadística

L. CC y Técnicas Estadísticas

D. Fisioterapia
M. Educación Primaria

L. CC. de la Act. Física

L. Química

L. Biología

L. Bioquímica

L. Ciencias Ambientales

L. Matemáticas

D. Enfermería

L. Medicina

L. Farmacia

L. C. y Tec. de los Alimentos

Arquitectura

Arquitectura Técnica

IT. Industrial (Electricidad)

IT. Industrial (Electrónica I.)

IT. Industrial (Mecánica)

I. Industrial

I. Química

IT. Telecom. (Sist. Electrón.)

IT. Telecom. (Telemática)

IT. Informática de Gestión

IT. Informática de Sistema

I. Informática
Hay asociación con origen

L. Filología Alemana

IT. Agrícola (Industrias Agrarias)
L. Ciencias Políticas

D. Educación Social

D. Logopedia
D. Nutrición y Dietética

L. Óptica y Optometría

D. Podología

L. Odontología

L. Veterinaria

IT. Minas (Expl. de Minas)

IT. Obras Públicas

IT. Topografía

I. Geológica

I. Caminos, Canales y Puertos

IT. Navegación Marítima

IT. Naval en Propulsión

IT. Industrial (Química I.)

IT. Industrial (Textil)

I. Organización Industrial

I. Materiales

I. Automática y Electrónica I.

IT. Telecom. (Sistemas Tel.)

IT. Telecom. (Sonido

Imagen)

I. Telecomunicaciones

I. Electrónica

IT. Agrícola (Expl. Agrop.)

IT. Agrícola (Hortofruticult.)

IT. Agrícola (Mecanización)

IT. Forestal (Expl. Forestal)

I. Agronómica

I. Forestal

IT. Aeronáutica (Aeronaveg.) 
Fachelli, Sandra \& Navarro-Cendejas, José (2015). Relación entre origen social e inserción laboral de los graduados universitarios. RELIEVE, 21 (2), art. 2. DOI: http://dx.doi.org/10.7203/relieve.21.2.7812

\section{Balance entre el nivel ocupacional y el nivel formativo}

\begin{tabular}{|c|c|c|}
\hline $\begin{array}{l}\text { D. Ciencias Empresariales } \\
\text { L. Filología Inglesa } \\
\text { L. Ciencias de la Actividad } \\
\text { Física y Deporte } \\
\text { No se pudo } \\
\text { determinar relación } \\
\text { con nivel formativo de } \\
\text { los padres } \\
\text { D. Relaciones Laborales } \\
\text { D. Trabajo Social } \\
\text { L. Ciencias del Trabajo } \\
\text { D. Gestión y Admón. Pública } \\
\text { L. Sociología } \\
\text { L. Comunicación Audiovisual } \\
\text { L. Periodismo } \\
\text { L. Publicidad y RP } \\
\text { L. Psicología } \\
\text { L. Pedagogía } \\
\text { L. Psicopedagogía } \\
\text { M. Educación Especial } \\
\text { M. Educación Física } \\
\text { M. Educación Infantil } \\
\text { M. Educación Musical } \\
\text { M. Lengua Extranjera } \\
\text { M. Educación Primaria } \\
\text { L. Química } \\
\text { L. Bioquímica } \\
\text { L. Ciencias Ambientales } \\
\text { L. Matemáticas }\end{array}$ & $\begin{array}{l}\text { D. Enfermería } \\
\text { D. Óptica y Optometría } \\
\text { L. Medicina } \\
\text { L. Farmacia } \\
\text { L. C. y Tec. de los Alimentos } \\
\text { Arquitectura } \\
\text { Arquitectura Técnica } \\
\text { IT. Industrial (Electricidad) } \\
\text { IT. Industrial (Electrónica I.) } \\
\text { IT. Industrial (Mecánica) } \\
\text { IT. Industrial (Química I.) } \\
\text { I. Química } \\
\text { IT. Telecom (S. Electrónicos) } \\
\text { IT. Telecom (Telemática) } \\
\text { IT. Informática de Gestión } \\
\text { IT. Informática de Sistemas } \\
\text { I. Informática } \\
\text { I. Agronómica } \\
\text { L. Antropología Soc. y Cul. } \\
\text { L. Historia } \\
\text { L. Adm. y Dir. de Empresas } \\
\text { L. Economía }\end{array}$ & L. CC. Políticas y de la Admón. \\
\hline & se pudo determinar relación & upacional de los padres \\
\hline
\end{tabular}

\section{Autores}

Fachelli, Sandra (sandra.fachelli@ub.edu).

Doctora en Sociología por la Universidad Autónoma de Barcelona. Es Profesora Asociada de Sociología en el Departamento de Sociología y Análisis de las Organizaciones, Facultad de Ciencias Económicas y Empresariales de la Universidad de Barcelona e Investigadora postdoctoral del Grupo de Investigación en Educación y Trabajo de la Universidad Autónoma de Barcelona. Principales líneas de investigación: desigualdad social, movilidad social, educación y trabajo, impacto de las políticas sociales. Dirección postal: Universitat Autònoma de Barcelona. Facultat de Ciències Polítiques i Sociologia Despatx B3/ -107. 08193 Bellaterra, Barcelona.

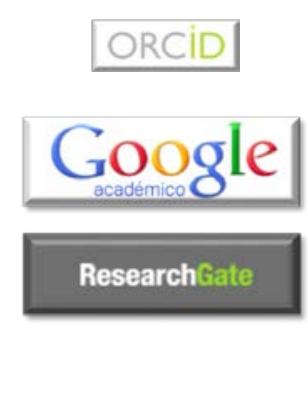

Navarro-Cendejas, José (jose-navarro@cide.edu).

Doctor en Sociología por la Universitat Autònoma de Barcelona, Maestría en Ciencias Sociales por la Universidad de Guadalajara (México). Catedrático del CONACYT comisionado al CIDE (México) dentro del Programa Interdisciplinario sobre Política y Prácticas Educativas. Principales líneas de trabajo: relación educación-trabajo e inserción laboral de los universitarios,

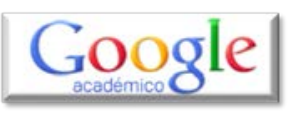

ResearchGate jóvenes y trayectorias educativas y laborales, competencias y empleabilidad. 


\section{RELIEVE}

\section{Revista ELectrónica de Investigación y EValuación Educativa E-Journal of Educational Research, Assessment and Evaluation}

[ISSN: 1134-4032]

(C) Copyright, RELIEVE. Reproduction and distribution of this articles it is authorized if the content is no modified and their origin is indicated (RELIEVE Journal, volume, number and electronic address of the document).

(C) Copyright, RELIEVE. Se autoriza la reproducción y distribución de este artículo siempre que no se modifique el contenido y se indique su origen (RELIEVE, volumen, número y dirección electrónica del documento). 